\title{
Patrick Chamoiseau, Hyperion Victimaire. Martiniquais épouvantable
}

\section{Emanuela Cacchioli}

\section{Q OpenEdition}

1 Journals

\section{Edizione digitale}

URL: http://journals.openedition.org/studifrancesi/1660

DOI: 10.4000/studifrancesi. 1660

ISSN: 2421-5856

\section{Editore}

Rosenberg \& Sellier

\section{Edizione cartacea}

Data di pubblicazione: 1 novembre 2014

Paginazione: 648-649

ISSN: 0039-2944

\section{Notizia bibliografica digitale}

Emanuela Cacchioli, «Patrick Chamoiseau, Hyperion Victimaire. Martiniquais épouvantable », Studi

Francesi [Online], 174 (LVIII | III) | 2014, online dal 01 novembre 2014, consultato il 18 septembre 2020. URL : http://journals.openedition.org/studifrancesi/1660; DOI : https://doi.org/10.4000/studifrancesi. 1660

Questo documento è stato generato automaticamente il 18 settembre 2020.

\section{(c)}

Studi Francesi è distribuita con Licenza Creative Commons Attribuzione - Non commerciale - Non opere derivate 4.0 Internazionale. 


\title{
Patrick Chamoiseau, Hyperion Victimaire. Martiniquais épouvantable
}

\author{
Emanuela Cacchioli
}

\section{NOTIZIA}

PATRICK CHAMOISEAU, Hyperion Victimaire. Martiniquais épouvantable, Paris, Éditions La Branche, 2013, coll. «Vendredi 13», pp. 317.

1 Nell'ultimo romanzo di Patrick Chamoiseau torna l'ispettore Évariste Pilon, un personaggio che il lettore ha già conosciuto in Solibo magnifique, uscito nel 1988. Il tempo è trascorso e per l'ispettore Pilon è giunta l'ultima notte di servizio di una carriera lunga e piuttosto monotona. Eppure il desiderio di incontrare «un tueur considérable, une bête de sang demeurée inconnue des forces de police» (p. 13) si realizza proprio quel venerdì 13 , data che costituisce il titolo della collana ed è una scelta obbligata per ogni poliziesco in essa pubblicato. L'ispettore è braccato con una pistola puntata e non può far altro che ascoltare il racconto di Hyperion Victimaire, il bandito giustiziere che compie ogni crimine per soddisfare la sua sete di rispetto e di ordine. Un personaggio complesso che, da un lato, è consapevole della barbarie dei suoi atti, ma che, dall'altro, compie azioni riprovevoli per correggere le imperfezioni di un sistema giudiziario impotente. La deposizione di Hyperion Victimaire, alla prima persona, frutto della trascrizione di alcuni stralci della sua confessione, si alterna alla narrazione in terza persona dell'ispettore. Tra i due personaggi, all'inizio opposti, si instaura una relazione basata sul racconto/ascolto che condurrà il lettore a definire il criminale come un alter ego di Évariste Pilon proprio in virtù della sete di giustizia che anima entrambi i personaggi. Dalla confessione di Hyperion Victimaire e dal confronto con l'ispettore emerge uno spaccato della Martinica attuale dominata dalla violenza, dai traffici, dalla povertà, dall'immigrazione, dalla prostituzione, dall'alcool e dalla droga. La situazione è il frutto della globalizzazione e della politica assimilazionista che impedisce alla Martinica di essere indipendente e diventare un'entità a sé. Una panoramica negativa alla quale si contrappone la Martinica magica di un tempo. Il 
criminale esprime questa nostalgia sin dalle prime pagine quando afferma di rimpiangere la «belle jeunesse, une belle jeunesse d'antan dans un pays d'antan» (p. 14). Nonostante la trama del romanzo sia basata sulla deposizione di questo terribile omicida, il suo racconto si rivela un inno nostalgico alla Martinica della tradizione e della ritualità che è stata cancellata dalla furia del tempo presente. Al giorno d'oggi, sull'isola violenza e miseria regnano sovrane e sono generate dal difficile contesto economico. A livello sociale sono l'individualismo e la frattura generazionale che regolano i rapporti tra giovani e anziani. I genitori falliscono la loro funzione dal momento che non riescono a trasmettere ai figli il rispetto. La conseguenza è l'impasse e una diffusa incomunicabilità che fossilizza ogni parte nella sua posizione. Di fronte alle riflessioni lucide del criminale, l'ispettore pare condividere le stesse opinioni e ne trova un'esemplificazione all'interno della propria famiglia: una moglie suicida dopo aver manifestato problemi di alcolismo e una figlia ribelle.

2 Nel romanzo è frequente il ricorso al creolo e ad una lingua ricca e vivace che sono un'ulteriore conferma del fatto che l'opera è un poliziesco atipico. Chamoiseau s'inserisce nella scia di altri autori già noti al pubblico che adottano il genere per rigenerarlo ed esprimere, in tal modo, una specificità caraibica e un'originalità creativa propria. 